\title{
Katalytische Aktivität der Serumlipase im kontinuierlichen titrimetrischen Test in Abhängigkeit von der Temperatur
}

\author{
Von W. Rick und M. Hockeborn \\ Institut für Klinische Chemie und Laboratoriumsdiagnostik der Universität Düsseldorf
}

(Eingegangen am 1. September/18. Dezember 1983)

Zusammenfassung: Die katalytische Aktivität der Pankreaslipase im Serum wurde mit dem kontinuierlichen titrimetrischen Test zwischen $20^{\circ} \mathrm{C}$ und $37^{\circ} \mathrm{C}$ gemessen. Es zeigte sich mit zunehmender Temperatur eine unlineare Substrathydrolyse mit der Zeit, deren Ausmaß und erstmaliges Auftreten durch die Probe, das Serumvolumen im Test und das verwendete Triglyceridgemisch beeinflußt wird. In 27 Untersuchungsserien ergab sich für den Temperaturbereich von $20^{\circ} \mathrm{C}$ bis maximal $32^{\circ} \mathrm{C}$ ein $\mathrm{Q}_{10}$-Wert von $1,45(\mathrm{~s}=0,03)$ und eine Aktivierungsenergie von $\mu=27,42 \pm 0,565 \mathrm{~kJ} / \mathrm{mol}(6550 \pm 135 \mathrm{cal} / \mathrm{mol} ; \overline{\mathrm{x}} \pm \mathrm{s})$.

Colipase-Zusatz bei niedrigen Meßtemperaturen bewirkte eine geringe Verschlechterung der Reaktionskinetik. In Anwesenheit des Cofaktors ist bei höheren Temperaturen ein deutlich positiver Einfluß auf die Substrathydrolyse mit der Zeit zu beobachten. Es gelang jedoch nicht, für alle Proben und Probevolumina eine Colipasekonzentration zu ermitteln, die zu einem linearen Reaktionsablauf führt.

Aus den vorliegenden Befunden geht hervor, daß für das verwendete Testverfahren eine Meßtemperatur von $25^{\circ} \mathrm{C}$ beibehalten werden sollte und daß die 1969 und 1982 beschriebenen Testbedingungen unverändert gelten. Werden diese Bedingungen eingehalten, so läßt sich der Zusatz von Colipase in der zur Zeit im Handel erhältlichen Qualität experimentell nicht begründen.

\section{The effect of temperature on the catalytic activity of serum lipase in the continuous titrimetric assay}

Summary: The catalytic activity of the pancreatic lipase in serum was measured between $20^{\circ} \mathrm{C}$ and $37^{\circ} \mathrm{C}$ by the continuous titrimetric assay. As the temperature was increased, the time course of substrate hydrolysis showed an increasing tendency to become non-linear. The degree of non-linearity and its time of onset depended on the sample, the volume of serum in the assay, and the composition of the triglyceride substrate mixture. Twenty seven series of investigations between $20^{\circ} \mathrm{C}$ and $32^{\circ} \mathrm{C}$ (maximal) showed a $\mathrm{Q}_{10}$ value of 1.45 ( $\mathrm{s}=0.03)$ and an activation energy of $\mu=27.42 \pm 0.565 \mathrm{~kJ} / \mathrm{mol}(6550 \pm 135 \mathrm{cal} / \mathrm{mol} ; \overline{\mathrm{x}} \pm \mathrm{s})$.

At low assay temperature, the addition of colipase caused a slight deterioration of the reaction kinetics, whereas at higher temperatures it caused a marked improvement in the time course of substrate hydrolysis. We were unable, however, to identify a fixed colipase concentration that would promote a linear reaction irrespective of sample origin and volume.

These results show that the assay should be performed at $25^{\circ} \mathrm{C}$, and that the test conditions described in 1969 and 1982 are valid without modification. If these conditions are observed, there is no experimental basis for the addition of colipase of the quality commercially available at present.

\section{Einführung}

Die vorliegende Arbeit wurde angeregt durch Bestrebungen in den Vereinigten Staaten, das Verfahren zur Messung der katalytischen Aktivität der Li- pase mittels kontinuierlicher Titration der durch enzymatische Hydrolyse aus einem Triglyceridgemisch freigesetzten $\mathrm{H}^{+}$-Ionen zu standardisieren (1), und durch die allgemeine Diskussion, bei welcher Tem- 
peratur Enzymaktivitäten generell gemessen werden sollen. Systematische Untersuchungen über die Abhängigkeit der katalytischen Aktivität der Serumlipase von der Meßtemperatur liegen bisher nicht vor. Wir prüften daher an verschiedenen Seren, die den Einsatz unterschiedlicher Serumvolumina ermöglichten, und unter Verwendung mehrerer Triglyceridgemische die Temperaturabhängigkeit der $\mathrm{Hy}$ drolyse des Substrats durch Lipase. Außerdem untersuchten wir den Einfluß von Colipase bei verschiedenen Reaktionstemperaturen.

\section{Material und Methoden}

Reagentien

1. Gummi arabisch, fein gepulvert, Ph Eur, Merck 4282, Charge 2579447.

2. Olivenöl verschiedener Chargen der Fa. Roth und DAB 8, Aluminiumoxid-gereinigt (2).

3. Olivenöl, Sigma 0-1500, Charge 62F01541.

4. Triolein, rein $95 \%$, Serva 37085,3 verschiedene Chargen. Die Herstellerangabe zur Reinheit des Präparats entspricht nicht dem tatsächlichen Trioleingehalt (3). Das unter der Bestellnummer 37086 von der $\mathrm{Fa}$. Serva angebotene und zur Lipasebestimmung empfohlene „Triolein" ist für den kontinuierlichen titrimetrischen Test ungeeignet. Dies ist aus den von der Firma übersandten Registrierungen ersichtlich (3) und wurde von uns an 3 Chargen nachgewiesen (4).

5. Triolein, über 99\%, Calbiochem 6450, Chargen 103079 und 201897.

6. Glykocholsäure, Natriumsalz, Calbiochem 360512, Chargen 810044 und 210135.

7. Colipase, aus Schweinepankreas, Boehringer 644099, Chargen $1371538,1482338,1123238$ und 1283238.

8. Natronlauge, $1 \mathrm{~mol} / \mathrm{l}$, Merck 9137.

9. Natronlauge, $0,1 \mathrm{~mol} / \mathrm{l}$, Merck 9141 .

10. Salzsäure, $1 \mathrm{~mol} / \mathrm{l}$, Merck 9057.

11. Salzsäure, $0,1 \mathrm{~mol} / \mathrm{l}$, Merck 9060 .

12. Bidest. Wasser, frei von Kohlendioxid.

13. Kalibrierpuffer:

Präzisionspuffer Radiometer S 1500 bzw. 1510

Phosphat-Pufferlösung, pH 6,88, 0,025 mol/1, Merck 7294.

Acetat-Pufferlösung, $\mathrm{pH} 4,66,0,1 \mathrm{~mol} / \mathrm{l}$ Essigsäure und 0,1 mol// Natriumacetat, Merck 7827.

14. Stickstoff, frei von Kohlendioxid.

15. Lipoclean (Frigen), Behringwerke OSVW 60/61, Charge 254002 A.

16. Aprotinin-Lösung, $20000 \mathrm{KIE} / \mathrm{ml}$, Trasylol, Bayer Leverkusen.

17. Human-Serumalbumin, trocken, reinst, Behringwerke ORHA 20.

18. Ammoniumsulfat zur Analyse, Merck 1217.

19. Polyethylenglycol-mono[p-(1,1,3,3-tetramethyl-butyl)-phenyl]-ether (Triton X-100), für die Gaschromatographie, Merck 12298.

\section{Lösungen}

1. Gummi arabicum-Lösung, $100 \mathrm{~g} / \mathrm{l}$ in bidest. Wasser. Die Herstellung entspricht den Angaben von 1969 (5), die vorhandenen Partikelchen wurden durch 10 Minuten langes Zentrifugieren bei etwa $2500 \mathrm{~g}$ entfernt.
2. Substratemulsion, 0,2 M Olivenöl bzw. Triolein in Lösung 1. Die Herstellung entspricht den Angaben von 1969 (5) unter Verwendung der unter Reagentien aufgeführten Triglyceride.

3. Na-Glykocholatlösung, $75 \mathrm{mmol} / \mathrm{l}$ in bidest. Wasser.

3,657 g Glykocholsäure, Natriumsalz, werden in bidest. Wạsser ad $100 \mathrm{ml}$ gelöst.

4. Natronlauge, $0,01 \mathrm{~mol} / \mathrm{l}$.

Die Herstellung entspricht den Angaben von 1969 (5).

5. Colipase-Stammlösung, $0,5 \mathrm{~g} / 1$ in physiologischer $\mathrm{NaCl}-\mathrm{Lö}=$ sung.

6. Humanalbuminlösung, $40 \mathrm{~g} / 1$ in physiologischer $\mathrm{NaCl}-\mathrm{Lösung}$. 7. Ammoniumsulfat-Stammlösung, $0,1 \mathrm{~mol} / \mathrm{l}$ in bidest. Wasser, pH-Wert auf 8,6 eingestellt.

8. Tritoñ $\mathrm{X}-100$-Lösung, $0,1 \mathrm{l} / 1$ bzw. $0,01 \mathrm{l} / 1$ in bidest. Wasser.

\section{Probenmaterial}

Bei den verwendeten Proben handelte es sich um:

Seren von Gesuñden,

Seren von Patienten mit akuten oder chronischen Pankreaserkrankungen,

Sammelserum, in dem die Pankreaslipase durch zweistündige Inkubation bei $56^{\circ} \mathrm{C}$ vollständig inaktiviert wurde,

Seren, die 24 Stunden bei $+4^{\circ} \mathrm{C}$ gegen physiologische $\mathrm{NaCl}-\mathrm{Lö-}$ sung dialysiert wurden,

Seren, die nach Vorschrift des Herstellers mị Lipoclean (Frigen) behandelt wurden.

\section{Meßanordnung}

Die Meßanordnung entsprach deñ Angaben von 1969 (5). Ebenso wurden von der Fa. Radiometer verwendet: pH-Meter PHM 64, Titrator TTT 80, Autobürette ABU 80, Registriergerät Servograph REC 80 mit Titrigraph-Modul REA 160 unter Benutzung der 1969 beschriebenen (5) Rühreinrichtung, Thermostatisierung, Titriergefäße, Elektroden und Bürettenspitze. Ziwischen dem mit thermostatisiertem Wasser durchströmtẹn Kupfermantel und dem Titrationsgefä $\beta$ aus Glas befanden sich zur Verbesserung des Wärmeübergangs einige Milliliter bidest. Wasser, dadurch wurde im Testansatz eine Temperaturkonstanz von $\pm 0,1^{\circ} \mathrm{C}$ erreicht. Die Meßtemperaturen betrugen $20,22,25,28$, $30,32,35$ und $37^{\circ} \mathrm{C}$.

\section{Methodik}

Prinzip, Ausführung, Auswertung und Berechnung entsprechend den Angaben von 1969 (5).

\section{Ergebnisse und Diskussion}

Analyse von Seren bei Meßtemperaturen zwischen 20 und $37^{\circ} \mathrm{C}$ ohne Zusatz von Colipase

\section{Reaktionsablauf bei unterschiedlichen Temperaturen}

Bei der Messung der katalytischen Aktivität der Lipase in verschiedenen Seren ergibt sich unter Verwendung der genannten Triglyceride (s. Reagentien 2-5) bei Temperaturen von $20-25^{\circ} \mathrm{C}$ in Abhängig-keit von der eingesetżten Enzymmenge ein linearer Substratumsatz bis zu einer Reäktionszeit von 60 Minuten. Diese Linearität ist in Anwesenheit von 
Glykocholat in optimaler Konzentration bei $28^{\circ} \mathrm{C}$ oder darüber nicht mehr gegeben. Ein nichtlinearer Substratumsatz in Abhängigkeit von der Temperatur ist auch bei Tietz \& Repique (6) an einem Serum bei $37^{\circ} \mathrm{C}$ dargestellt. Ähnliche Befunde wurden von Granon \& Sémériva (7) mit reiner Schweinepankreaslipase als Enzymquelle gegenüber verschiedenen Triglyceriden erhoben.

Die Ursache des nicht geradlinigen Reaktionsablaufs bei Meßtemperaturen über $28^{\circ} \mathrm{C}$ konnte nicht geklärt werden. Eine Verschiebung des Optimums der Na-Glykocholatkonzentration mit zunehmender Temperatur konnte ausgeschlossen werden. Soweit in Testansätzen ein linearer Substratumsatz beobachtet wird, ist das Optimum unverändert, ebenso bleibt die Hemmwirkung durch höhere Gallensalzkonzentrationen nachweisbar (Abb. 1 und 2). Bei den Temperaturen, die bereits den genannten Effekt der nichtlinearen Substrathydrolyse bewirken, ergibt sich bei Auswertung des Laugeverbrauchs in den ersten Minuten nach Beginn der Registrierung eindeutig, daß keine Änderung im Verhalten gegenüber Glykocholat auftritt. Die so ermittelten Werte streuen zwar erheblich, lassen aber die typische Abhängigkeit der katalytischen Aktivität von der Gallensalzkonzentration erkennen. Da eine nichtlineare

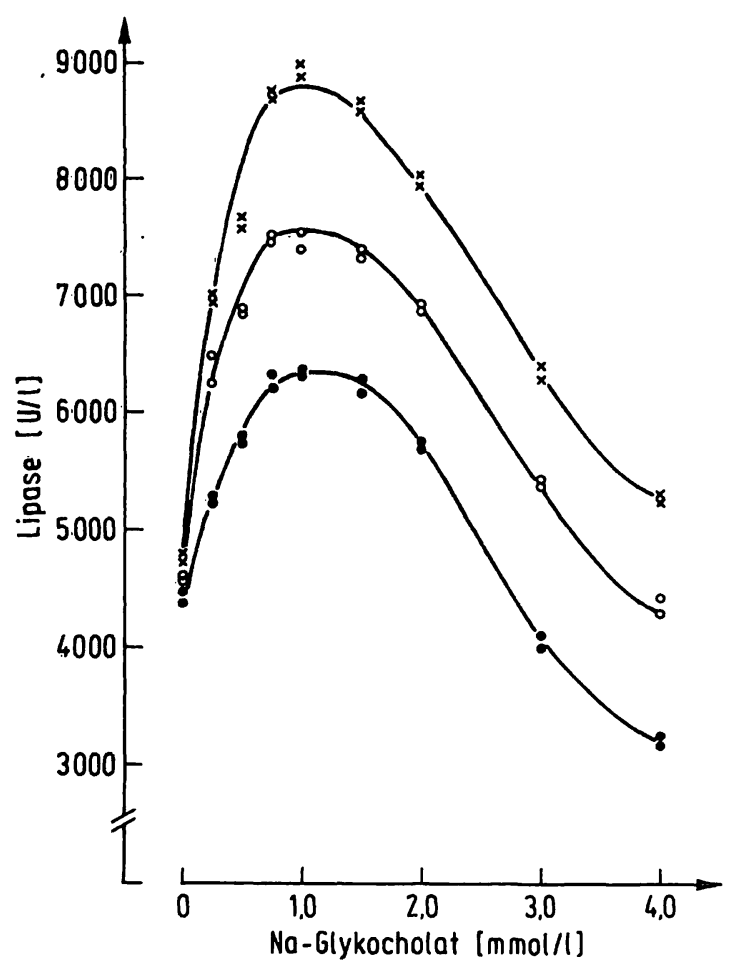

Abb. 1. Kontinùierlicher titrimetrischer Test. Abhängigkeit der katalytischen Aktivität von der NaGlykocholatkonzentration bei verschiedenen Reaktionstemperaturen.

Triglyceridgemisch s. Reagens 4 .

$50 \mu l$ Serum Ba. im Test.

(-) $20^{\circ} \mathrm{C}$

O-O $25^{\circ} \mathrm{C}$

$\mathrm{x}-\mathrm{x} 30^{\circ} \mathrm{C}$

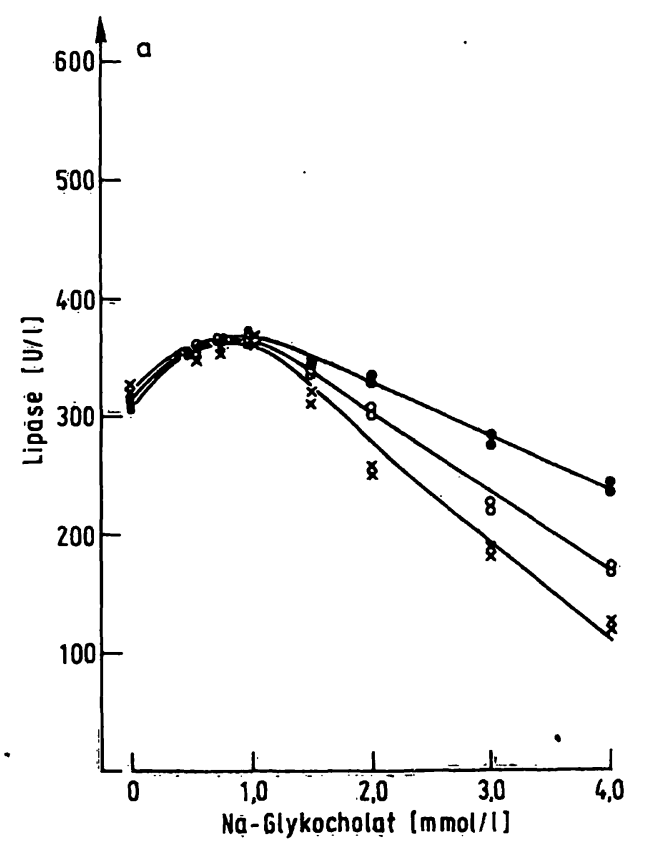

b

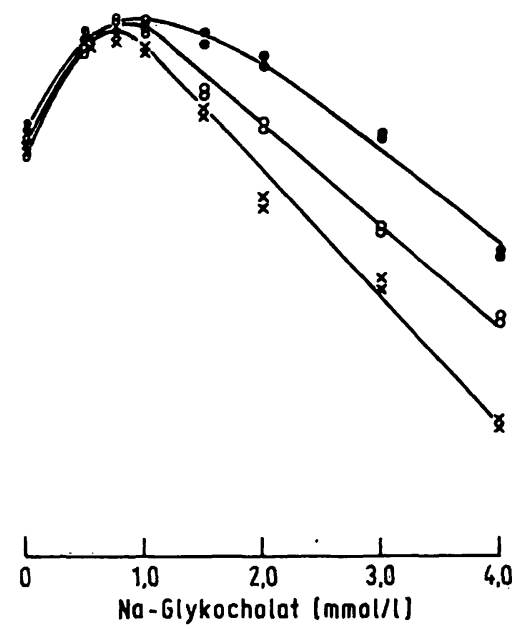

c
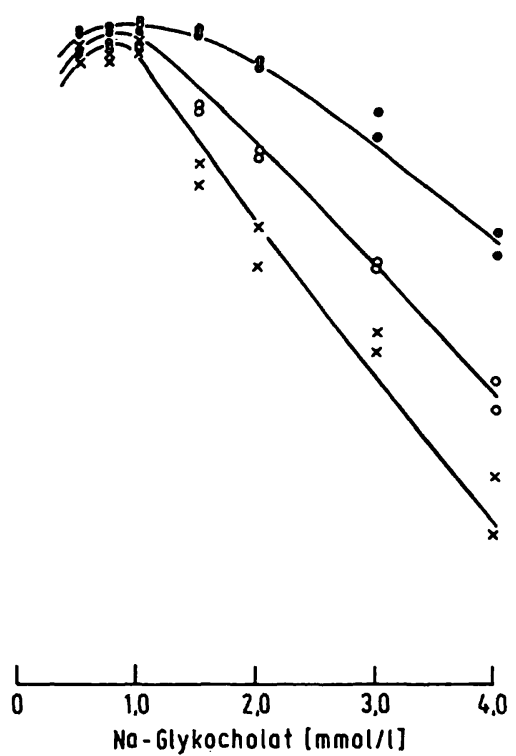

Abb. 2. Kontinuierlicher titrimetrischer Test. Abhängigkeit der katalytischen Aktivität von der Na-Glykocholatkonzentration, dem eingesetzten Serumvolumen und der Reaktionstemperatur.

a) $20^{\circ} \mathrm{C}$

b) $25^{\circ} \mathrm{C}$

c) $30^{\circ} \mathrm{C}$

(Ohne Zusatz von $\mathrm{Na}$-Glykocholat lag bei $30^{\circ} \mathrm{C}$ bereits eine inkonstante Hydrolysegeschwindigkeit vor.)

Triglyceridgemisch s. Reagens 2 .

$200 \mu \mathrm{l}$ Serum Wi. im Test

O-O $500 \mu$ Serum Wi. im Test

$x-x 1000 \mu l$ Serum Wi. im Test 
Hydrolyse mit der Zeit im gleichen Diagramm schwer darstellbar ist, sind in Abbildung 1 und 2 die bei den Temperaturen $a b 32{ }^{\circ} \mathrm{C}$ gefundenen Werte nicht eingetragen. Die von uns ermittelte temperaturunabhängige Wirkung des Gallensalzes steht im Widerspruch zu Angaben von Fritz \& Melius (8), die Olivenöl als Substrat verwendeten, sowie von Granon \& Sémériva (7), die Triglyceride kurz- und mittelkettiger Fettsäuren benutzten. Die Autoren fanden mit zunehmender Temperatur eine Verschiebung der optimalen Gallensalzkonzentration zu höheren Werten hin. In den genannten Arbeiten werden allerdings gereinigte Lipasepräparationen als Enzymquelle verwendet und es dienen - soweit dargestellt - außerordentlich stark unlineare Registrierungen zur Auswertung.

Auffällig war bei den Versuchen, bei denen die katalytische Aktivität in Abhängigkeit von der eingesetzten Na-Glykocholatkonzentration gemessen wurde, $\mathrm{da}$ in Ansätzén ohne Gallensalz - je nach eingesetzter Probe - eine Temperaturerhöhung praktisch keinen (Abb. 1) oder nur einen geringen Effekt (Abb. 2) zeigte. Wenn in Abwesenheit von Na-Glykocholat eine Aktivitätssteigerung mit der Temperatur beobachtet wurde, ergab sich kein geradliniger Zusammenhang in der Darstellung nach Arrhenius (9). Auch diese Beobachtung ist ein Beispiel dafür, daß zuverlässige Aussagen über die katalytische Aktivität eines Enzyms nur möglich sind, wenn in Anwesenheit optimaler Konzentrationen aller Reaktionspartner gearbeitet wird.

Die von Szasz (10) diskutierte verminderte Substrataffinität von Enzymen bei höheren Temperaturen ist nicht als Ursache für die inkonstante Hydrolysegeschwindigkeit anzusehen. Wurde die Substratkonzentration dadurch variiert, daß eine Verdünnung der Emulsion mit bidest. Wasser erfolgte, so ergab sich (bei $37^{\circ} \mathrm{C}$ gemessen) in Ansätzen mit reduziertem Triglyceridgehalt eine noch wesentlich schlechtere Kinetik. Bei Auftragung der zuerst registrierten Werte nach Hofstee (11) fand sich kein geradliniger Zusammenhang zwischen $v$ und $\frac{v}{[S]}$. Wurde die Substratemulsion mit Gummi arabicum-Lösung verdünnt, so zeigten alle Ansätze eine etwa gleich stark ausgeprägte nichtlineare Substrathydrolyse mit der Zeit. Unter vergleichbarer Auswertung ergab sich kein Anhalt für eine gegenüber $25^{\circ} \mathrm{C}$ veränderte Substrataffinität. Da auch die Substratkonzentration im Test sehr hoch ist - sie beträgt das 40fache der $K_{\mathrm{m}}$ (unabhängig davon, ob als Konzentration oder als Oberfläche angegeben) - ergäbe sich auch bei einer herabgesetzten Substrataffinität keine Erklärung für die beobachtete unlineare und verminderte katalytische Aktivität in Abhängigkeit von der Temperatur. Die Versuchsergebnisse lassen andererseits auch den Schluß zu, daß Gummi arabicum bei erhöhten Temperaturen keine Hemmwirkung auf die Substrathydrolyse ausübt und daß die in den wäßrigen Substratverdünnungen reduzierte Calciumkonzentration keine Verbesserung der Kinetik zur Folge hat.

Weiterhin inkubierten wir Substratemulsionen 24 Stunden lang bei $25^{\circ} \mathrm{C}$ bzw. $37^{\circ} \mathrm{C}$. Untersuchungen der Tröpfchengrößenverteilung mit dem Thrombocytenkanal des Coulter Counter Model S Plus ergaben keinen Hinweis für eine Änderung dieser Kenngröße in Abhängigkeit von der Temperatur. In beiden Fällen fand sich das Maximum der Tröpfchenvolumina bei 2,5 fl. Allerdings ist bei diesem Vorgehen zu berücksichtigen, daß im Meßgerät eine hohe Verdünnung des Substrats mit einer nicht zu temperierenden Verdünnungslösung erfolgt. Ebenso ergab die mikroskopische Betrachtung der Substratemulsionen keine Unterschiede. Granon \& Sémériva (7) fanden mit Tributyrin als Substrat keine wesentliche Änderung der Oberflächenspannung in Abhängigkeit von der Temperatur. Aufgrund dieser am Substrat gewonnenen Ergebnisse ist aber nicht auszuschließen, dạ höhere Temperaturen Veränderungen an der Grenzfläche zwischen Triglyceridtröpfchen und wäßriger Phase bewirken.

Wurden Proben 24 Stunden bei $+4{ }^{\circ} \mathrm{C}$ gegen physiologische $\mathrm{NaCl}$-Lösung dialysiert, zeigte sich keine Änderung der Kinetik bei den verschiedenen Reaktionstemperaturen. Somit ist eine temperaturabhängige Hemmung der enzymatischen Reaktion durch dialysierbare Hemmstoffe ausgeschlossen.

Ein direkter Temperatureffekt auf das Enzymmolekül im Serum ist nicht nachweisbar; auch 12 Stunden bei $37^{\circ} \mathrm{C}$ inkubierte Proben zeigten bei einer Meßtemperatur von $25^{\circ} \mathrm{C}$ innerhalb der Fehlerbreite eine unveränderte katalytische Aktivität.

Borgström (12) diskutiert eine irreversible Inaktivierung von Lipase mit zunehmender Temperatur. an der Grenzfläche zwischen dem wasserunlöslichen Substrat und der wäßrigen Phase. Hinweise auf einen solchen Mechanismus ergeben sich auch aus unseren Versuchen. Kühlt man einen bei $37^{\circ} \mathrm{C}$ registrierten Testansatz, der eine kontinuierliche $A b$ nahme des Substratumsatzes erkennen läßt, schnell auf $25^{\circ} \mathrm{C}$ ab und titriert weiter, so zeigt sich bei der verminderten Meßtemperatur zwar wieder eine konstante Umsatzgeschwindigkeit, jedoch wird die in Ansätzen ohne thermische Vorbehandlung bei $25^{\circ} \mathrm{C}$ gemessene Aktivität nicht erreícht. 
Einfluß von Probe, Na-Glykocholat und Triglyceridgemisch auf die Substrathydrolyse bei unterschiedlichen Temperaturen

Je höher das Serumvolumen im Test ist, desto niedriger liegt die Temperatur, bei der erstmals eine inkonstante Hydrolysegeschwindigkeit beobachtet wird. Der temperaturabhängige unlineare Reaktionsablauf ist aber nicht nur an das eingesetzte Probevolumen gebunden, sondern hängt auch von der verwendeten Probe selbst ab (Tab. 1). Andererseits ist zu beobachten, daß das Ausmaß des nichtlinearen Substratumsatzes mit der Zeit um so größer ist, je geringer das Serumvolumen im Test ist (Abb. 3a und b).

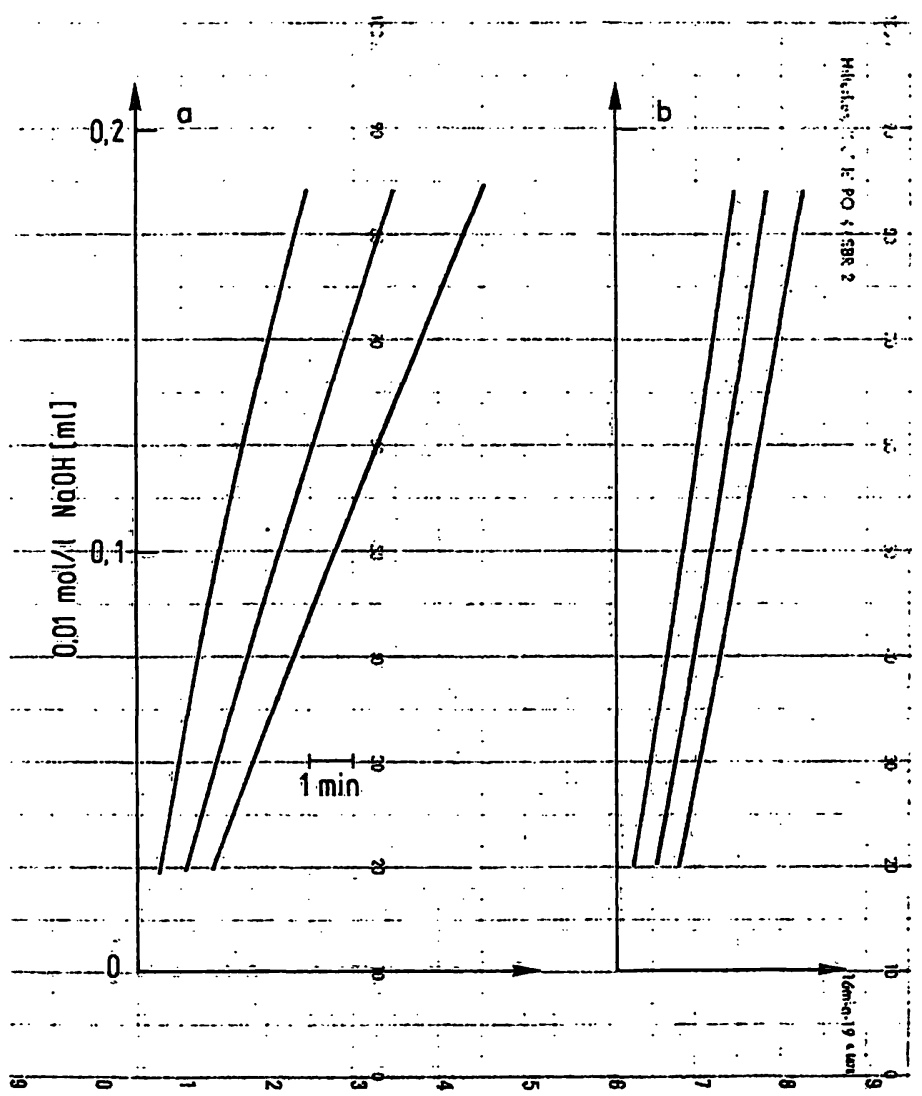

Abb. 3. Kontinuierlicher titrimetrischer Test.

Einflu $B$ des Serumvolumens im Test auf die Reaktionskinetik bei $37^{\circ} \mathrm{C}$.

a) $50 \mu \mathrm{l}$ Serum Ba. im Test.

Bei Auswertung des anfänglich registrierten Laugeverbrauchs ermittelte katalytische Aktivitäten: $11000,7020,5200 \mathrm{U} / \mathrm{l}$.

b) $50 \mu \mathrm{l}$ Serum $\mathrm{Ba} .+0,95 \mathrm{ml}$ inaktiviertes Sammelserum im Test

Ermittelte katalytische Aktivitäten: 13900, 12800, $11000 \mathrm{U} / 1$

Triglyceridgemisch s. Reagens 3 .

Optimale Na-Glykocholatkonzentration im Test.

Ohne Zusatz von Colipase.

Es wurde jeweils ein Testansatz über cinen längeren Zeitraum titriert.
Tab. 1. Kontinuierlicher titrimetrischer Test.

Temperaturen, bis zu denen in Abhängigkeit von der Probe und dem eingesetzten ${ }^{-V}$ olumen der gleichen Probe ein linearer Substratumsatz mit der Zeit vorliegt. Triglyceridgemisch s. Reagens 4.

Optimale Na-Glykocholatkonzentration im Test.

Serum

Serumvolumen/Test Temperatur, bis zu der linearer Substratumsatz vorliegt

$(\mu \mathrm{l})$

$\left({ }^{\circ} \mathrm{C}\right)$

\begin{tabular}{lrl}
\hline Ba. & 20 & 32 \\
& 50 & 30 \\
Wi. & 100 & 28 \\
& 200 & 32 \\
& 500 & 30 \\
Gr. & 1000 & 28 \\
& 20 & 32 \\
Ma. & 50 & 32 \\
& 100 & 30 \\
B. & 500 & 32 \\
& 1000 & 28 \\
Ke. & 50 & 30 \\
& 100 & 30 \\
Ho. & 100 & 30 \\
& 200 & 28 \\
Se. & 500 & 30 \\
& 1000 & 28 \\
& 500 & 28 \\
& 1000 & 25
\end{tabular}

In welcher Weise das einzelne Serum die Hydrolyse beeinflußt, ist unklar. Eine ähnliche individuelle Wirkung der Probe auf den Substratumsatz ist auch bei Variation der Glykocholatkonzentration nachweisbar $(5,13)$. Hier sind ebenso Serum und Serumvolumen für den Zeitpunkt und den Umfang der Hemmwirkung durch das Gallensalz von Bedeutung, ohne daß hierfür eine Erklärung gefunden werden konnte.

Als Ursache der „besseren“ Kinetik in Gegenwart größerer Serumvolumina bei höheren Meßtemperaturen (z. B. $\left.37^{\circ} \mathrm{C}\right)$ ist vor allem die Anwesenheit von Albumin zu diskutieren. Brockerhoff (14) konnte zeigen, daß die nichtlineare Umsatzrate bei $37^{\circ} \mathrm{C}$ von - allerdings grobdispersem - Tributyrin durch reine Lipase in Anwesenheit von Rinderserumalbumin in eine Reaktion nullter Ordnung überging. Auch Borgström et al. (15) beschreiben die stabilisierende Wirkung von Serumalbumin auf Pankreaslipase. 
Na-Glykocholat zeigt einen günstigen Einfluß auf den Reaktionsablauf. In Ansätzen ohne Gallensalz tritt die beschriebene inkonstante Hydrolyse bei niedrigeren Temperaturen auf als wenn Na-Glykocholat zugesetzt wird (z.B. ersichtlich aus Abb. 2c). Zusatz des Aktivators in Konzentrationen, die bereits eine Hemmung der katalytischen Aktivität bewirken, führt bei Ansätzen mit sehr geringen Probevolumina (z.B. $50 \mu \mathrm{l} /$ Test) zu einer Verbesserung der Kinetik, nicht aber zu völlig linearen Substratumsätzen. Ein derartiger Effekt von Na-Glykocholat auf die Linearität ist bei der Analyse von Seren, die den Einsatz hoher Probevolumina (0,5-1,0 ml) ermöglichen und bei denen die inkonstante Hydrolysegeschwindigkeit ohnehin nicht so stark ausgeprägt ist, nicht nachweisbar.

Wie das Gallensalz bei höheren Reaktionstemperaturen die Triglyceridspaltung beeinflußt, ist nicht bekannt. Eine linearisierende Wirkung durch sehr niedrige Konzentrationen von Na-Glykocholat ist auch bei $25^{\circ} \mathrm{C}$ in Ansätzen mit geringen Proteinmengen (z.B. verdünnter Duodenalsaft, gereinigte Lipasepräparationen) zu beobachten (13).

Vergleichsuntersuchungen an verschiedenen Ölen zeigen, daß die Temperatur, bei der erstmals eine nichtlineare Substrathydrolyse beobachtet wird, auch vom verwendeten Triglyceridgemisch abhängig ist. Ebenso wie der Beginn wird auch das Ausmaß des nichtlinearen Substratumsatzes durch das verwendete Öl mitbestimmt.

Welche Faktoren in den Triglyceridpräparationen die temperaturabhängige inkonstante Hydrolysegeschwindigkeit beeinflussen, ist nicht bekannt. Sicher ist bisher nur, daß die beschriebenen Effekte nicht mit dem Triolein-Gehalt des Öls zusammenhängen.

\section{Abhängigkeit der katalytischen Aktivität von der Meßtemperatur}

Weiterhin prüften wir bei verschiedenen Temperaturen die Hydrolyse des Substrats in Abhängigkeit vom eingesetzten Probevolumen. In dem Bereich, in dem eine geradlinige Beziehung zwischen Substratumsatz und Zeit beobachtet wird, besteht bei den gewählten Temperaturen eine Proportionalität zwischen eingesetzter Serummenge und Laugeverbrauch pro Minute (Abb. 4). Sobald ein nichtlinearer Reaktionsablauf auftritt, ist keine korrekte Auswertung der registrierten Kurven möglich und somit auch keine zuverlässige Aussage über die direkte Abhängigkeit der gemessenen katalytischen Aktivität vom eingesetzten Probevolumen.

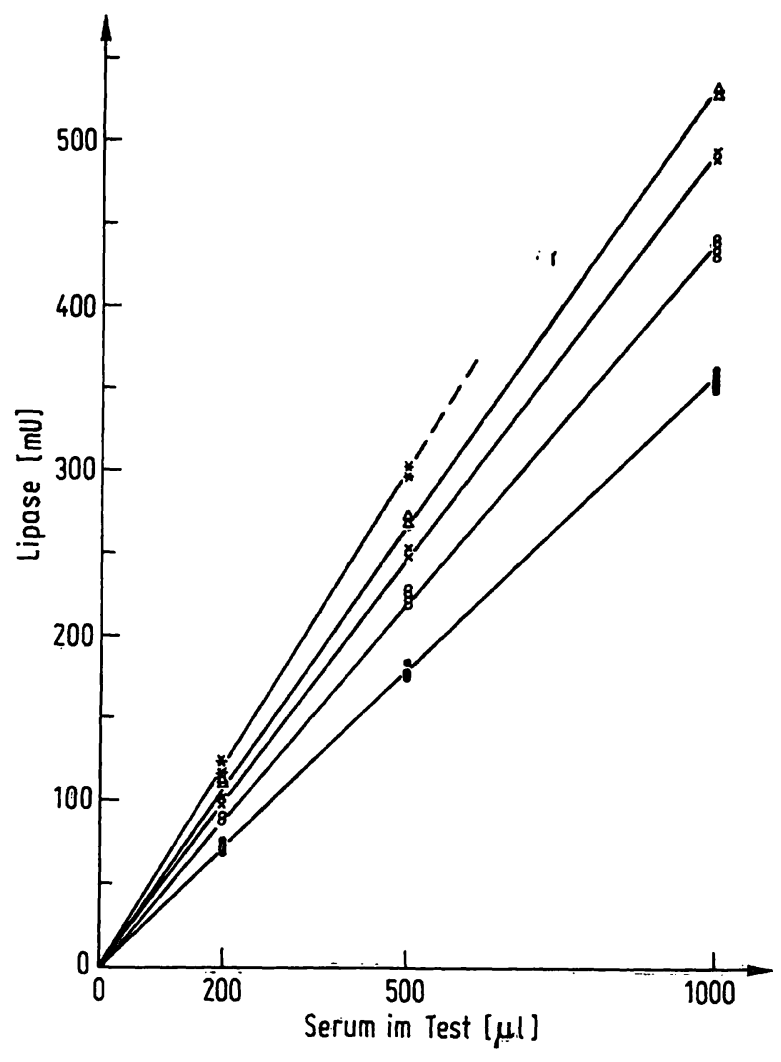

Abb. 4. Kontinuierlicher titrimetrischer Test.

Ergebnisse der Analyse unterschiedlicher Probevolumina bei Temperaturen, die einen linearen Substratumsatz mit der Zeit gewährleisten.

Triglyceridgemisch s. Reagens 4.

Optimale Na-Glykocholatkonzentration im Test:

Ohne Zusatz von Colipase.

200, 500 und $1000 \mu$ Serum Wi. im Test.

D-O $20^{\circ} \mathrm{C}$

O-O $25^{\circ} \mathrm{C}$

$\mathrm{x}-\mathrm{x} 28^{\circ} \mathrm{C}$

$\triangle-\triangle 30^{\circ} \mathrm{C}$

$\star$ - $\star 32^{\circ} \mathrm{C}$

Werden die Ergebnisse aus Mehrfachbestimmungen, bei denen in Anwesenheit optimaler Na-Glykocholatkonzentrationen ein linearer Substratumsatz mit der Zeit vorliegt, in Abhängigkeit von der Temperatur nach Arrhenius (9) aufgetragen, so zeigt sich eine geradlinige Beziehung (Abb. 5). Der $\mathrm{Q}_{10}$-Wert - ermittelt zwischen 20 bis maximal $32^{\circ} \mathrm{C}-$, der aus 27 Untersuchungsserien errechnet wurde (z.T. wurden Verdünnungen der gleichen Probe analysiert), beträgt 1,45 mit einer Standardabweichung von 0,03 . Der gefundene $\mathrm{Q}_{10}$-Wert liegt in dem Bereich, der auch für andere Hydrolasen beschrieben wurde (16). Die Aktivierungsenergie ergibt sich $\mathrm{zu} \mu=27,42 \pm$ $0,565 \mathrm{~kJ} / \mathrm{mol}(6550 \pm 135 \mathrm{cal} / \mathrm{mol} ; \overline{\mathbf{x}} \pm \mathrm{s}) ;$ dies entspricht etwa dem von Sarda \& Desnuelle (17) an Schweinepankreaslipase in Gegenwart von Taurocholat gefundenen Wert $(\mu \equiv 21,935 \mathrm{~kJ} / \mathrm{mol}=5240$ $\mathrm{cal} / \mathrm{mol}$ ) und den Angaben von Sizer \& Josephson (18) für die Hydrolyse von Tributyrin durch Schweinepankreasslipase oberhalb von $0_{:}^{\circ} \mathrm{C}(\mu=31,82 \mathrm{~kJ} /$ $\mathrm{mol}=7.600 \mathrm{cal} / \mathrm{mol})$. 


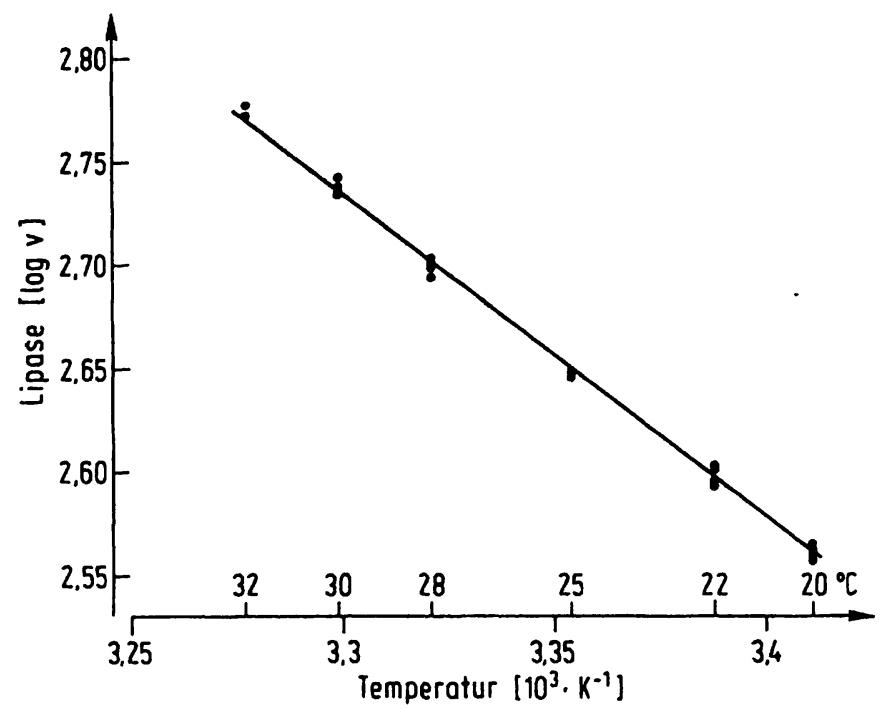

Abb. 5. Kontinuierlicher titrimetrischer Test.

Abhängigkeit der Enzymaktivität von der Temperatur, Auswertung nach Arrhenius (9).

Q $_{10}$-Wert (ohne Zusatz von Colipase) $=1,49$

Triglyceridgemisch s. Reagens 4.

Optimale Na-Glykocholatkonzentration im Test. $500 \mu \mathrm{l}$ Serum Co. im Test.

Werden die bei hohen Meßtemperaturen aus nichtlinearen Reaktionsabläufen errechneten Ergebnisse nach Arrhenius (9) dargestellt, so wird auch bei Berücksichtigung des anfänglich registrierten Laugeverbrauchs eine zunehmende Abweichung von der theoretisch zu erwartenden katalytischen Aktivität gefunden (zu ersehen aus Abb. 10). Da beim kontinuierlichen titrimetrischen Test die Aktivitätsmessung nicht unmittelbar nach Start der Reaktion möglich ist (s. unten) und steigende Temperaturen eine zunehmende „Verschlechterung" der Kinetik bewirken, muß im Falle der Lipase angenommen werden, da $\beta$ die sich ergebende Abweichung in der Auftragung nach Arrhenius (9) ausschließlich auf der bereits diskutierten zunehmenden Inaktivierung des Enzyms durch steigende Temperaturen an der Phasengrenzfläche vor Beginn der Registrierung des Laugeverbrauchs beruht. Bergmeyer (19) macht für die Abweichung von der Geraden nach Arrhenius (9), wie sie an zahlreichen Ẽnzymen zu beobachten -ist (10), eine Änderüng der wirksamen Enzymkonzentration durch die Temperaturerhöhung verantwortlich. Eine „Verschlechterung“ der Kinetik muß damit jedoch nicht verbunden sein.

Analyse von Seren bei Meßtemperaturen $z$ wischen 20 und $37^{\circ} \mathrm{C}$ mit Zusatz von Colipase

Zur Prüfung der Frage, welchen Einfluß Colipase auf den Reaktionsablauf bei verschiedenen Tempe- raturen hat, setzten wir den Cofaktor in unterschiedlichen Konzentrationen (molares Verhältnis Colipase:Lipase $=1: 1$ bis $10000: 1)$ in den Test ein.

\section{Beeinflussung des Reaktionsablaufs durch Colipase bei niedrigen Temperaturen}

Im Bereich derjenigen Meßtemperaturen, bei denen in Ansätzen ohne Colipase ein geradliniger Substratumsatz nachweisbar ist, führt der Zusatz dieses Proteins zu einer „Verschlechterung“ der Kinetik (Abb. 6). Dieser Effekt ist in Ansätzen mit großen Volumina mäßig aktiver Seren deutlicher als bei Einsatz kleiner Volumina hochaktiver Proben. Ein hoher Colipaseüberschuß führt zu stärkeren Abweichungen von der Linearität. Schließlich zeigt auch das verwendete Triglyceridgemisch einen Einfluß auf die Kinetik in Gegenwart des Cofaktors.

Wie bereits 1982 beschrieben (13), ist bei der Analyse unterschiedlicher Proben und Serumvolumina eine exakte Standardisierung des Registrierbeginns nicht möglich. Dies beruht darauf, daß der pH-Wert der Probe von Serum zu Serum schwankt, daß je nach eingesetztem Volumen eine mehr oder weniger stark ausgeprägte Änderung der $\mathrm{H}^{+}$-Konzentration des Gesamtansatzes erfolgt, die evtl. eine Zugabe kleiner Mengen verdünnter Lauge oder Säure (z. B. $0,1 \mathrm{~mol} / \mathrm{l}$ ) erfordert, und daß die katalytischen Aktivitäten der Proben sehr unterschiedlich sein können. Während bei linearem Reaktionsablauf eine reproduzierbare Auswertung der Registrierungen über einen langen Zeitraum möglich ist, ergibt sich bei der Bewertung von Ansätzen mit inkonstanter Hydrolysegeschwindigkeit - je nachdem, zu welchem Zeitpunkt mit der Aufzeichnung des Laugeverbrauchs begonnen werden kann - zwangsläufig eine geringe Präzision. So zeigen die an Ansätzen mit Colipase aus dem zunächst registrierten Natronlaugeverbrauch ermittelten katalytischen Aktivitäten je nach verwendetem Serum und eingesetzter Colipasekonzentration eine mehr oder weniger große Streuung um die ohne den Cofaktor gefundenen Werte (z. B. zu ersehen aus Abb. 10).

Fügt man den Cofaktor zu laufenden Ansätzen zu, so zeigt sich die gleiche „Verschlechterung“ der Reaktionskinetik wie bei Zugabe vor Beginn der Titration.

Wird Șerum mit Colipase bei $25^{\circ} \mathrm{C}$ vorinkubiert und die Mischung zur Substratemulsion mit Na-Glykocholat zugesetzt, so ist keine bessere Linearität zu beobachten.

Infolge der inkonstanten Hydrolysegeschwindigkeit bei Zusatz von Colipase kann der Zusammenhang 


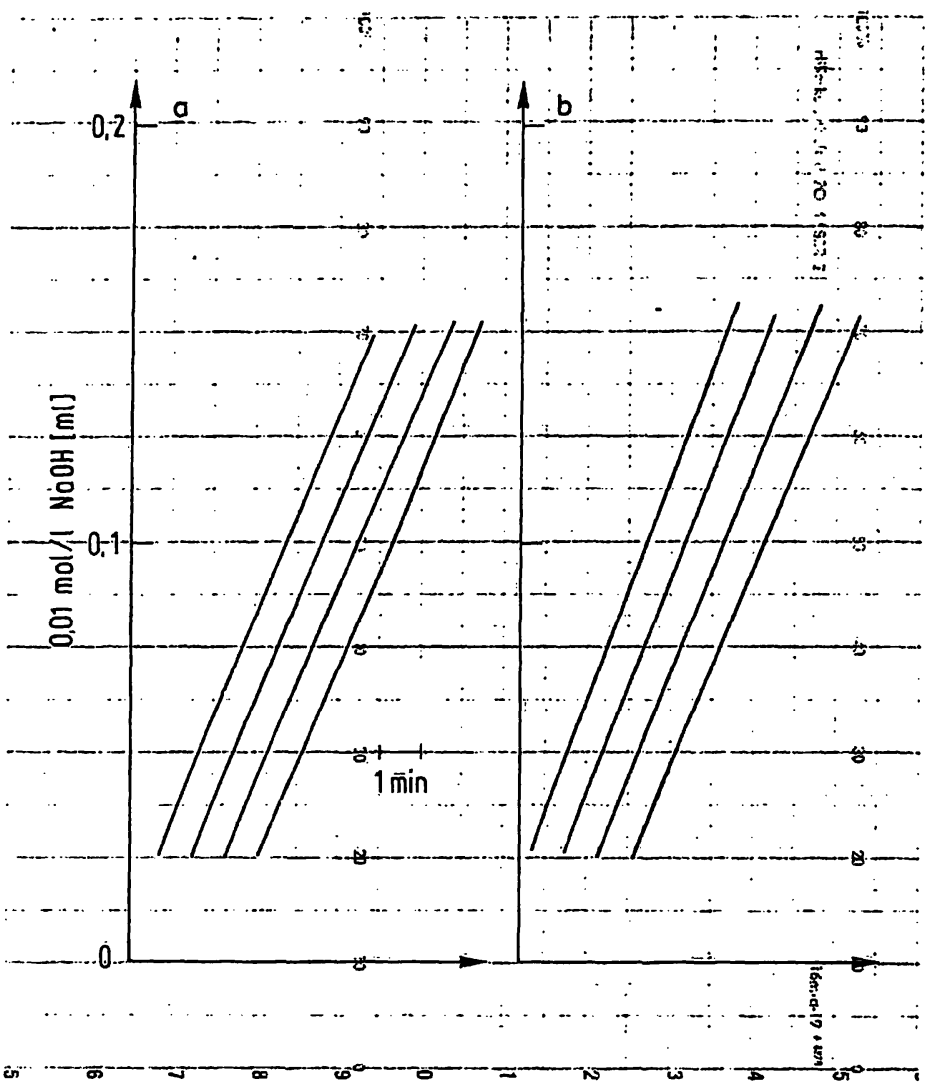

Abb. 6. Kontinuierlicher titrimetrischer Test.

Einfluß von Colipase auf die Reaktionskinetik bei einer Meßtemperatur von $25^{\circ} \mathrm{C}$

a) ohne Colipase im Test

Ermittelte katalytische Aktivitäten: 2380, 2360, 2350, 2370 U/l.

b) $333 \mu \mathrm{g} / \mathrm{l}$ Colipase im Test

Ermittelte katalytische Aktivitäten: 2650, 2540, 2420, $2340 \mathrm{U} / \mathrm{l}$.

Triglyceridgemisch s. Reagens 2.

Optimale Na-Glykocholatkonzentration im Test.

$100 \mu \mathrm{l}$ Serum B. im Test.

Es wurde jeweils ein Testansatz über einen längeren Zeitraum titriert.

zwischen eingesetztem Probevolumen und Meßsignal bei verschiedenen Temperaturen nicht ausreichend exakt beurteilt werden.

Die beschriebene Verschlechterung der Reaktionskinetik in Anwesenheit von Colipase bei den Meßtemperaturen, die in Abwesenheit des Proteins eine lineare Substrathydrolyse erkennen lassen, ist wahrscheinlich nicht auf einen einzigen Mechanismus zurückzuführen. Die Präparation der Colipase umfaßt u. a. auch eine Fällung mit Ammoniumsulfat $(20,21$, 22). In den verwendeten Chargen des Cofaktors ermittelten wir mit der Glutamatdehydrogenase-Reaktion (23) geringe - wenn auch unterschiedliche Konzentrationen an $\mathrm{NH}_{4}^{+}$-Ionen. Wird Ammoniumsulfat in entsprechender Menge zu Titrationsansätzen zugesetzt, so ist eine vergleichbare Verschlechterung der Reaktionskinetik feststellbar. Eine Erhöhung der $\mathrm{NH}_{4}^{+}$-Konzentration führt zu einer zunehmenden Unlinearität. Dies entspricht Beobachtungen, daß die Verwendung großer Volumina Colipase den beschriebenen Effekt der inkonstanten Hydro- lyse verstärkt und daß bei verschiedenen Chargen Colipase das Ausmaß der Unlinearität schwankt. Fügt man Testansätzen höhere Konżentrationen Ammoniumsulfat $\mathrm{zu}$ (Endkonzentration 0,33-3,3 $\mathrm{mmol} / \mathrm{l}$ ), wird neben der deutlichen Zunahme der Unlinearität ein proportionaler Anstieg des Laugeverbrauchs beobachtet. In Leerwerten ohne bzw. mit Zusatz von inaktiviertem Sammelserum und auch in Abwesenheit von Substrat wird nach Zugabe der genannten Mengen Ammoniumsulfat durch die Freisetzung von Ammoniak bei pH 8,6 ein etwa gleichgroßer konzentrationsabhängiger Verbrauch an Titrationsflüssigkeit beobachtet. Dieser Laugeverbrauch verläuft jedoch im Gegensatz zu den Probehaltigen Ansätzen linear. Die auftretende Unlinearität in Gegenwart von Ammoniumionen ist an die Anwesenheit aktiver Lipase gebunden. Wie die $\mathrm{Ki}$ netik beeinflußt wird, ist unklar. Es muß eine direkte Wirkung auf die enzymatische Reaktion angenommen werden, wobei auch die Eigenschaften des verwendeten Substrats für das Ausm̧aß von Bedeutung sind. 
Das verwendete Colipasepräparat enthält nach Angaben des Herstellers noch Proteasen. Mit Tosyl- $L$ arginin-methylester (TAME) als Substrat (24) bestimmten wir an einer Charge die Trypsinaktivität; sie entsprach $4,2 \mu \mathrm{g}$ aktivem Trypsin pro mg Lyophilisat. Um den Einfluß der Protease auszuschalten, versetzten wir Colipaselösung mit einem ausreichend hohen Úberschuß Aprotinin, so daß kein aktives Trypsin mehr nachweisbar war. Prüften wir diese Mischung im kontinuierlichen titrimetrischen Test, so ergab sich kein Unterschied gegenüber der Verwendung von Colipase ohne Aprotinin-Zusatz.

Die oben bereits beschriebenen Versuche bezüglich der Tröpfchengrößenverteilung in der Emulsion wurden auch in Gegenwart von Colipase ausgeführt, ergaben jedoch keine wesentlichen Veränderungen gegenüber den erwähnten Resultaten und somit keine Erklärung für die Unlinearität.

Ebenso konnte eine Reaktion mit im Serum enthaltenen Substraten ursächlich ausgeschlossen werden. Dialysiert man Seren 24 Stunden bei $+4{ }^{\circ} \mathrm{C}$ gegen physiologische $\mathrm{NaCl}-$ Lösung, so ergibt sich keine Änderung bezüglich der Kinetik in An- oder Abwesenheit des Cofaktors. Eine Extraktion der Seren mit Lipoclean (Frigen) bewirkte keine Linearisierung des Reaktionsablaufs in Gegenwart von Colipase.

Da bei der Darstellung von Colipase nach Canioni et al. (22) Triton X-100 verwendet wird, prüften wir dessen Einfluß auf das Testsystem. In Gegenwart von $0,4 \mathrm{mmol} / 1$ des Detergens wird bereits eine deutliche Hemmung der Lipase beobachtet, die Linearität jedoch nicht beeinträchtigt.

Die Anwesenheit von Colipase macht es möglich, dem Ansatz Na-Glykocholat in höheren Konzentrationen zuzusetzen (Ubersicht bei 1.c. $(15 ; 13)$ ). Auch dies bewirkte jedoch keine grundlegende Verbesserung des Reaktionsablaufs.

In früheren Untersuchungen (13) wurde der beschriebene Einfluß auf die Kinetik nicht beobachtet. Der Grund hierfür kann in dem verwendeten Colipasepräparat zu suchen sein. Aus Schweinepankreas sind mehrere verschieden große Proteine mit Colipaseaktivität dargestellt worden (20), im Pankreassekret findet sich eine Vorstufe (Pro-Colipase) (25). Die reproduzierbare Isolierung eines Colipasepräparats mit definierter Aktivität ist offenbar nicht unproblematisch $(15,25)$. So ist eine unterschiedliche Zusammensetzung der einzelnen Colipase-Chargen denkbar. Es ist aber auch nicht auszuschließen, $\mathrm{da} \beta$ das früher verwendete Triglyceridgemisch eine wesentliche Rolle spielte.
Ein weiteres ungelöstes Problem stellt der durch die Colipaselösung bedingte Laugeverbrauch gegenüber der Substratemulsion in Abwesenheit von Serumlipase dar. Versetzt man Leerwerte ohne bzw. mit inaktiviertem Sammelserum, dialysiertem inaktivierten Sammelserum oder Humanalbuminlösung $(40 \mathrm{~g} / 1)$ mit dem Cofaktor oder einem ColipaseAprotinin-Gemisch, so ergibt sich ein linearer Natronlaugeverbrauch (Abb. 7). Dieser Verbrauch ist von der eingesetzten Menge Colipase abhängig, zwischen 100 und $500 \mu \mathrm{g}$ Colipase im Test ergab sich jedoch keine direkte Proportionalität zwischen eingesetzter Menge Cofaktor und Verbrauch an Titrationsflüssigkeit. Die titrierte Menge Natronlauge ist auch von der Charge der verwendeten Colipase abhängig. Größenordnungsmäßig täuschen $500 \mu \mathrm{g}$ des Cofaktors eine Lipaseaktivität von etwa $120 \mathrm{mU}$ $\left(25^{\circ} \mathrm{C}\right)$ vor. Setzt man Gummi arabicum-Lösung ohne Triglycerid ein und mißt die Leerreaktion in Gegenwart von Colipase, so ist der Laugeverbrauch sehr stark reduziert und nicht sicher von Null zu unterscheiden.

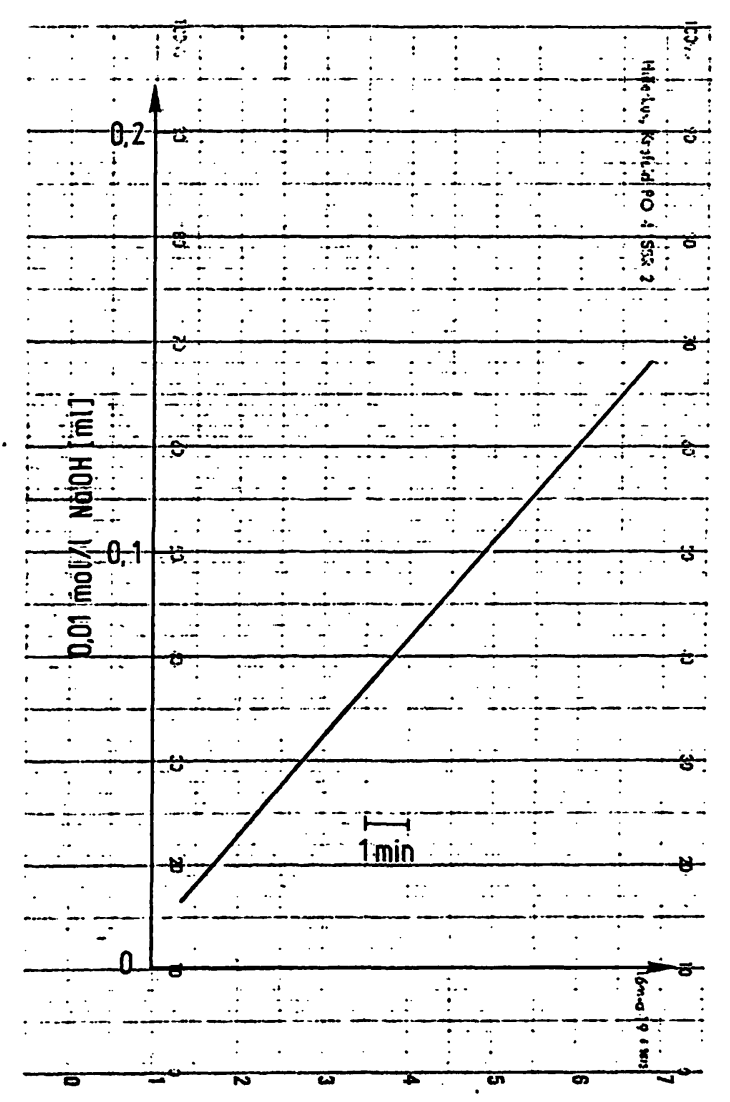

Abb. 7. Kontinuierlicher titrimetrischer Test.

Laugeverbrauch bei Einsatz von $500 \mu \mathrm{g}$ Colipase (Charge 1123238) in einen Testansatz mit 1,0 ml inaktiviertem Sammelserum und optimaler Na-Glykocholatkonzentration.

Triglyceridgemisch s. Reagens 5. Meßtemperatur $25^{\circ} \mathrm{C}$. 
Das Vorhandensein des Ammoniumsalzes im Präparat erklärt diesen Leerwert nicht. Die in dem Cofaktor enthaltene Menge $\mathrm{NH}_{4}^{+}$-Ionen reicht für diesen Effekt nicht aus, außerdem ist der durch Ammoniumionen bedingte $\mathrm{NaOH}-$ Verbrauch nicht an die Anwesenheit von Substrat gebunden.

Wird Colipaselösung 2 Stunden bei $+56^{\circ} \mathrm{C}$ gehalten, ist der Verbrauch an Titrationsflüssigkeit sehr stark reduziert; daraus ist zu schließen, daß der Leerwert zum überwiegenden Teil durch eine enzymatische Reaktion verursacht sein dürfte. Die erwähnte thermische Behandlung reicht aus, um die Lipaseaktivität in einer Serumprobe vollständig zu hemmen. Colipasepräparate, die ohne ausreichende Hitzeinaktivierung hergestellt wurden, können mit Lipase verunreinigt sein. Da keine Untersuchungen über die Inaktivierung von Schweinepankreaslipase in Gegenwart hoher Colipasekonzentrationen vorliegen, ist es denkbar, daß die im Colipasepräparat enthaltene Lipàse nicht vollständig denaturiert ist. Lairon et al. (26) beschreiben eine Inaktivierung ihrer Colipasepräparation in Anwesenheit von Trypsin bereits bei $37^{\circ} \mathrm{C}$. Inkubierten wir ein ColipaseAprotinin-Gemisch 2 Stunden bei $56^{\circ} \mathrm{C}$, so stellten wir keinen Unterschied in der Restaktivität im Vergleich zu einer Inaktivierung des Cofaktors in Abwesenheit des Proteasen-Hemmstoffs fest. Der Leerwert kann auch die Resultante mehrerer Effekte sein. Weitere Untersuchungen zu dieser Frage waren wegen des hohen Preises für den Cofaktor nicht möglich.

\section{Beeinflussung des Reaktionsablaufs durch Colipase bei höheren Temperaturen}

Die beschriebene nichtlineare Substrathydrolyse bei Temperaturen über $28^{\circ} \mathrm{C}$ ist durch den Zusatz von Colipase beeinflußbar. Bei kleinen Serumvolumina im Test wird die Kinetik wesentlich verbessert, wenngleich kein völlig linearer Substratumsatz erreicht wird (Abb. 8a). In den meisten untersuchten hochaktiven Proben werden in Gegenwart des Cofaktors anfänglich katalytische Aktivitäten gefunden, die in dem theoretisch zu erwartenden Bereich (Auftragung nach Arrhenius (9)) liegen. In Tabelle 2 sind die Ergebnisse, die an einem hochaktiven Serum $(100 \mu \mathrm{l} / \mathrm{Test})$ bei $37^{\circ} \mathrm{C}$ gewonnen wurden, in Abhängigkeit von der Colipasekonzentration dargestellt. Es wurde jeweils ein Ansatz über einen längeren Zeitraum titriert, vom zeitlichen Ablauf her sind die senkrechten Spalten vergleichbar. Es ist auffällig, daß die beobachtete Linearisierung keine direkte Abhängigkeit von der eingesetzten Colipasekonzentration zeigt und daß die Zugabe größerer Mengen des Proteins nicht zu einer völlig geradlinigen Kine-

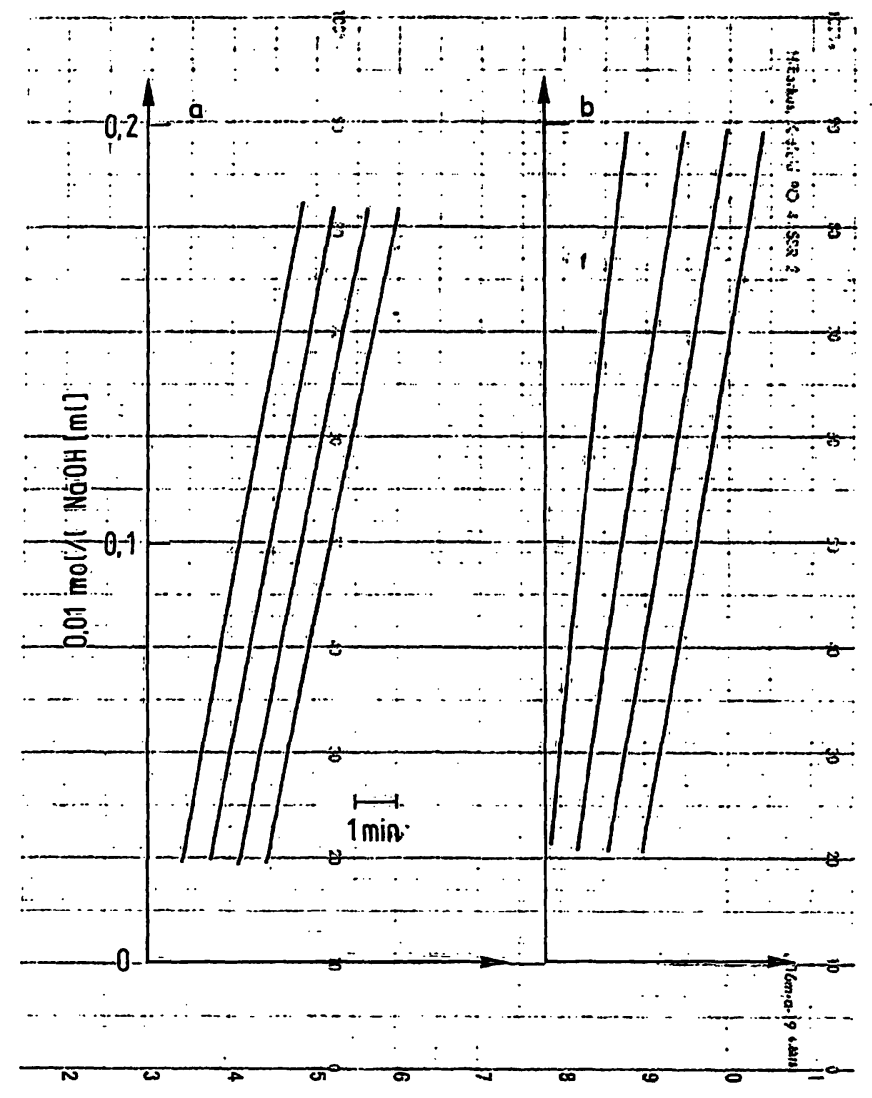

Abb. 8. Kontinuierlicher titrimetrischer Test.

Einfluß des Serumvolumens auf den Reaktionsablauf bei $37^{\circ} \mathrm{C}$ in Gegenwart von Colipase.

a) $50 \mu \mathrm{l} \mathrm{Serum} \mathrm{Ba}$. (Sollwert $11600 \mathrm{U} / \mathrm{l}$ ) und $333 \mu \mathrm{g}$ Colipase/l im Test.

Ermittelte katalytische Aktivitäten: 10840, 10400, $10100,9750 \mathrm{U} / \mathrm{l}$.

b) $1,0 \mathrm{ml}$ Serum $\mathrm{H}$. (Sollwert $1200 \mathrm{U} / \mathrm{l}$ ) und $3,33 \mathrm{mg}$ Colipase/l im Test.

Bei Auswertung des anfänglich registrierten Laugeverbrauchs ermittelte katalytische Aktivitäten: 987, $675,600,585 \mathrm{U} / \mathrm{l}$.

Triglyceridgemisch s. Reagens 3.

Optimale Na-Glykocholatkonzentration im Test.

Es wurde jeweils ein Testansatz über einen längeren Zeitraum titriert.

tik führt, wie sie ohne Colipase an dieser Probe zwischen 20 und $30^{\circ} \mathrm{C}$ vorlag.

Setzt man dagegen höhere Volumina (z.B. 1,0 ml) einer Probe mit mäßig erhöhter katalytischer Aktivität in den Test ein, so ist es nicht möglich, eine Colipasekonzentration zu ermitteln, bei der eine annähernd lineare Hydrolyse beobachtet wird und somit eine reproduzierbare Auswertung erfolgen kann. Bei sehr hohem Colipaseüberschuß kommt es wieder zur „Verschlechterung“ der Kinetik. Dies könnte auf der von Borgström (12) an reinen Proteinen beobachteten kompetitiven Hemmung der Lipase durch einen 1000 fachen Úberschuß an Colipase beruhen. Bei einer Reihe von Seren wird auch der theoretisch nach Arrhenius (9) zu erwartende Wert nicht erreicht. In Abbildung $8 \mathrm{~b}$ ist ein Beispiel dargestellt, wobei Colipase in einem 1000fachen mola- 
Tab. 2. Kontinuierlicher titrimetrischer Test.

Einflu $B$ der Konzentration an Colipase im Test auf die Reaktionskinetik bei $37^{\circ} \mathrm{C}$.

Triglyceridgemisch s. Reagens 4.

Optimale Na-Glykocholatkonzentration im Test.

$100 \mu \mathrm{l}$ Serum Mi. (Sollwert $9100 \mathrm{U} / \mathrm{I}$ ) im Test.

Es wurde jeweils ein Testansatz über einen längeren Zeitraum titriert, die Auswertung erfolgte in vergleichbaren Zeitabständen.

Die in Gegenwart hoher Colipasekonzentrationen ermittelten Leerwerte sind nicht berücksichtigt.

Die z.T. erheblichen Abweichungen vom Sollwert beruhen auf der bereits vor Beginn der Auswertung stark unterschiedlichen Unlinearität des Reaktionsablaufs bei der Meßtemperatur von $37^{\circ} \mathrm{C}$.

\begin{tabular}{crl}
\hline $\begin{array}{l}\text { Colipase } \\
(\mu \mathrm{g} / \mathrm{l})\end{array}$ & Ansatz & $\begin{array}{l}\text { Lipase } \\
(\mathrm{U} / \mathrm{l})\end{array}$ \\
\hline 0 & I & $\begin{array}{l}4750,4130,4030,3680 \\
4850,4440,4130,3880\end{array}$ \\
0,33 & II & $5090,4670,4330,4100$ \\
& I & $4960,4540,4280,3960$ \\
3,3 & II & $7000,6750,6550,6320$ \\
33 & I & $6500,6380,6130,5810$ \\
333 & II & $9000,8620,8250,8060$ \\
& I & $8750,8380,8000,7850$ \\
667 & II & $8950,8400,8130,7830$ \\
& II & $8750,8450,8130,7750$ \\
1670 & I & $8250,8150,7880,7620$ \\
3330 & II & $8200,8120,7830,7680$ \\
& I & $8250,7950,7750,7500$ \\
& II & $8180,7890,7700,7420$ \\
\hline
\end{tabular}

ren Ưberschuß vorhanden war. Geringere Konzentrationen an Cofaktor ergaben an dieser Probe keine bessere Linearität.

Das Ausmaß der nichtlinearen Substrathydrolyse bei höheren Temperaturen in Anwesenheit von Colipase ist neben dem verwendeten Serum und dem Probevolumen auch vom eingesetzten Triglyceridgemisch abhängig.

Borgström (27) führt als Erklärung für die konstantere Substrathydrolyse bei hohen Meßtemperaturen in Gegenwart von Colipase an, daß der Cofaktor das Enzymprotein vor der temperaturibedingten Denaturierung an der Phạsengrenzfläche schützt. Diese Hypothese wird durch folgende Beobachtung unterstützt: Setzt man bei $37^{\circ} \mathrm{C}$ laufenden Ansätzen nachträglich Colipase zu, so wird nicht mehr dieselbe Annäherung an die theoretisch zu erwartenden Aktivitäten erzielt, als wenn der Cofaktor dem Testsystem von Anfang an zugefügt wird (Abb. 9). Daß nachträglich zu einem Ansatz zugefügte Colipase nicht den gleichen Effekt hat, entspricht auch den Erfahrungen mit nachträglich zugesetzten Gallensalzen $(6,13)$.
Eine vollständige Linearisierung der Substrathydrolyse in Gegenwart von Colipase war auch durch Variation der Meßbedingungen nicht möglich. Werden Probe und Colipase gemischt und unterschiedlich lange bei $37^{\circ} \mathrm{C}$ vorinkubiert, so zeigt sich nach $\mathrm{Zu}$ gabe des Gemisches zu Gallensalz-haltigem Substrat keine konstantere Hydrolysegeschwindigkeit. Eine Vorinkubation von Serum, Colipase und Na-Glykocholat ist deshalb nicht möglich, weil der Zusatz des Gallensalzes in der Menge, die im Testansatz einer optimalen Konzentration entspricht, in Abhängigkeit von der vorhandenen Serummenge eine mehr oder weniger ausgeprägte Verminderung der Lipaseaktivität bewirkt. Während bei Verwendung von 1,0 ml Serum praktisch keine Herabsetzung der Reaktionsgeschwindigkeit gefunden wurde, zeigten $50 \mu l$ einer Probe mit hoher katalytischer Aktivität (13000 U/l) unter den beschriebenen Bedingungen bei $37^{\circ} \mathrm{C}$ eine rasche Inaktivierung; in einem halblogarithmischen Maßstab ergab sich bei Auswertung des jeweils anfänglich registrierten Laugeverbrauchs in einem Zeitraum von 60 Minuten ein geradliniger Abfall, aus dem sich eine Halbwertszeit von $25 \mathrm{Mi}$ nuten ermitteln ließ.

Ebenso wie bei niedrigen Meßtemperaturen ist auch bei $37^{\circ} \mathrm{C}$ durch den Einsatz höherer Na-Glykocholatkonzentrationen keine befriedigende Änderung der Reaktionskinetik zu erzielen.

Substratverdünnungen in bidest. Wasser führten bei einer Meßtemperatur von $37^{\circ} \mathrm{C}$ auch in Anwesenheit von Colipase nicht $\mathrm{zu}$ einem geradlinigen $\mathrm{Zu}$ sammenhang zwischen $v$ und $\frac{v}{[S]}$. Wurde Gummi arabicum als Verdünnungsmedium benutzt, so zeigte sich bei Auswertung des anfänglichen Laugeverbrauchs ebenso wie in Abwesenheit des Cofaktors keine veränderte Substrataffinität im Vergleich zu einer Temperatur von $25^{\circ} \mathrm{C}$. In allen Verdünnungen bewirkte die Anwesenheit von Colipase bei $37^{\circ} \mathrm{C}$ im Vergleich zu Cofaktor-freien Ansätzen eine bessere Kinetik.

Zusammenfassend ist an einer Probe $(1,0 \mathrm{ml}$ Serum im Test) das beschriebene Verhalten in der Auftragung nach Arrhenius (9) im Vergleich zu Cofaktorfreien Ansätzen bei den verschiedenen Meßtemperaturen aufgezeigt (Abb. 10). Hier wurde - analog zu Tabelle 2 - jeweils ein Ansatz über eine geraume Zeit registriert und in Abständen ausgewertet. Der Ubersicht halber sind Mehrfachwerte nicht eingetragen. Auch aus dieser Darstellung ist zu ersehen, daß die Colipase-haltigen Ansätze eine inkonstante $\mathrm{Hy}$ drolysegeschwindigkeit zeigen und daß (bei $37^{\circ} \mathrm{C}$. dargestellt) die Verwendung hoher Konzentrationen des Cofaktors keine Verbesserung bewirkt. 


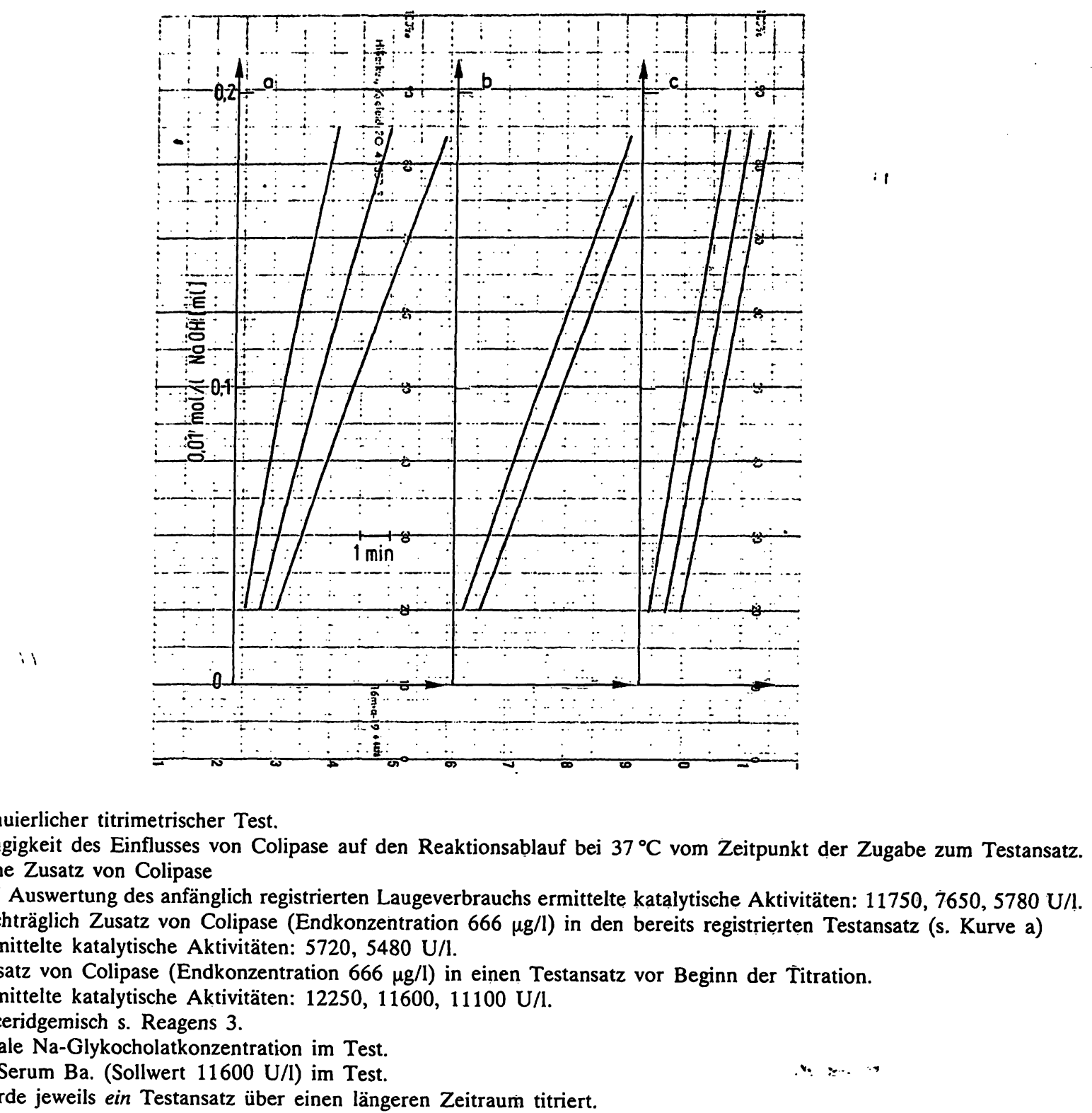

Abb. 9. Kontinuierlicher titrimetrischer Test.

Abhängigkeit des Einflusses von Colipase auf den Reaktionsablauf bei $37^{\circ} \mathrm{C}$ vom Zeitpunkt der Zugabe zum Testansatz. a) ohne Zusatz von Colipase

Bei Auswertung des anfänglich registrierten Laugeverbrauchs ermittelte katalytische Aktivitäten: 11750, 7650, $5780 \mathrm{U} / 1$.

b) nachträglich Zusatz von Colipase (Endkonzentration $666 \mu \mathrm{g} / \mathrm{l}$ ) in den bereits registrierten Testansatz (s. Kurve a)

Ermittelte katalytische Aktivitäten: $5720,5480 \mathrm{U} / 1$.

c) Zusatz von Colipase (Endkonzentration $666 \mu \mathrm{g} / \mathrm{l}$ ) in einen Testansatz vor Beginn der Titration.

Ermittelte katalytische Aktivitäten: 12250, 11600, $11100 \mathrm{U} / \mathrm{l}$

Triglyceridgemisch s. Reagens 3.

Optimale Na-Glykocholatkonzentration im Test

$50 \mu$ Serum Ba. (Sollwert $11600 \mathrm{U} / \mathrm{l}$ ) im Test.

Es wurde jeweils ein Testansatz über einen längeren Zeitraum titriert.

\section{Ergebnisse in Abhängigkeit vom verwende- ten Triglyceridgemisch}

Auf die Unterschiede der beschriebenen Effekte in Abhängigkeit vom eingesetzten Substrat kann in diesem Rahmen nicht detailliert eingegangen werden. Lediglich 3 Befunde sind hervorzuheben. Die erwähnte Serum-abhängige Unlinearität bei hohen Meßtemperaturen war bei Verwendung des unter Reagens 4 genannten Öls am stärksten ausgeprägt und bei Reagens 3 am wenigsten deutlich. Das synthetische Triolein von hoher Reinheit (Reagens 5) zeigte bei Einsatz geringer Probevolumina auch bei $25^{\circ} \mathrm{C}$ eine unlineare Substrathydrolyse, die jedoch durch Zusatz von inaktiviertem Sammelserum zu beseitigen war. Das Gallensäureoptimum variierte bei den verschiedenen Ölen geringfügig, es lag zwischen $0,75-1,25 \mathrm{mmol} / 1 \mathrm{Na}-$ Glykocholat.
In zahlreichen Publikationen (z.B. 7, 27, 28, 29) werden nichtlineare Substratumsätze bei Meßtemperaturen von $25^{\circ} \mathrm{C}$ oder darunter beschrieben. Hierbei ist $z u$ berücksichtigen, daß das Ziel solcher Untersuchungen meist nicht die Ausarbeitung optimaler Testbedingungen ist. Als Ursache für derartige Reaktionsverläufe sind der Dispersionsgrad des Substrats, eine nicht optimale Konzentration von Gallensalzen, Calciumionen oder Natriumchlorid sowie der geringe Proteingehalt der verwendeten $\mathrm{Li}$ pasepräparationen zu diskutieren. Es sei auch erwähnt, daß zahlreiche der im Handel erhältlichen Olivenöl- oder Trioleinpräparate nicht die Anforderungen eines linearen Substratumsatzes gewährleisten (30). 


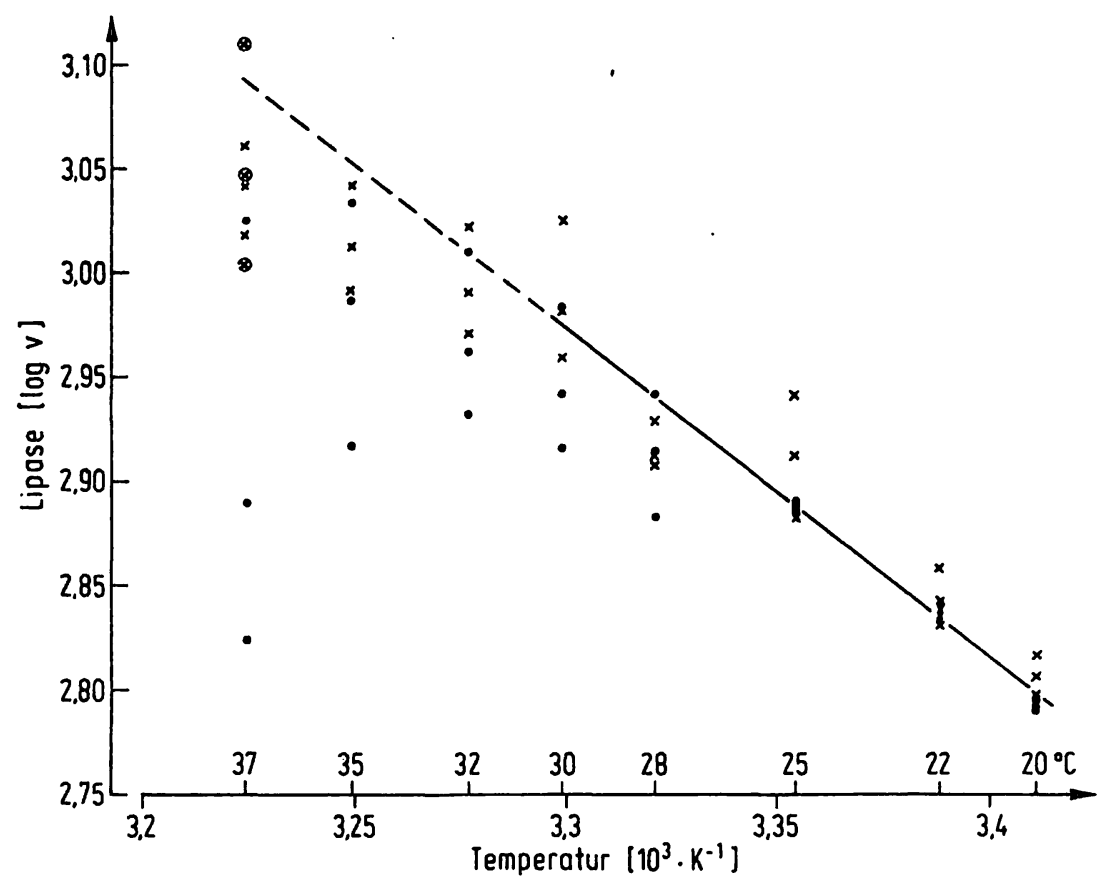

Abb. 10. Kontinuierlicher titrimetrischer Test.

Abhängigkeit der Enzymaktivität von der Temperatur, Auswertung nach Arrhenius (9).

$Q_{10}$-Wert (ohne Colipase) $=1,50$

Triglyceridgemisch s. Reagens 3 .

Optimale Na-Glykocholatkonzentration im Test.

$1,0 \mathrm{ml}$ Serum M. im Test.

Es wurde jeweils ein Testansatz über einen längeren Zeitraum titriert.

o ohne Colipase

x $333 \mu \mathrm{g} / \mathrm{l}$ Colipase im Test

® $3,33 \mathrm{mg} / \mathrm{l}$ Colipase im Test

\section{Schlußbetrachtung}

Borgström et al. (15) haben die außerordentlichen Schwierigkeiten, das komplizierte Zusammenspiel in vivo zwischen Pankreaslipase, Cofaktor, Substrat, Gallensäuren, Gallenlipiden, Nahrungsproteinen, Phospholipase $\mathrm{A}_{2}$, Pharynxlipase, Fettsäuren, Calcium, 'Wasserstoffionen u.a. zu verstehen, eindrucksvoll dargestellt. Auch die zur Bestimmung der katalytischen Aktivität der Lipase verwendeten kontinuierlichen Titrationsverfạhren stellen ein äußerst kompliziertes System dar, in dem das benutzte Substrat, seine Aufbereitung, der Emulgator und dessen Konzentration, die Art und das Volumen der Probe (20-1000 $\mu \mathrm{l}$ Serum), der Cofaktor (Spezies, Molekülgröße), Calciumionen, Gallensalze (Art und Konzentration), der pH-Wert und die Temperatur eine Rolle spielen. Ưber die Wechselwirkungen dieser einzelnen Komponenten in vitro gibt es bisher nur Hypothesen (31-37). Auch für die in Abhängigkeit vom verwendeten Serum und Triglyceridgemisch bei Temperaturen von $28^{\circ} \mathrm{C}$ oder mehr beobachteten nichtlinearen Reaktionsabläufe kann eine Inaktivierung der Lipase an der Grenzfläche der Fetttröpfchen' nur diskutiert werden, experimentelle
Beweise hierfür liegen nicht vor. Andererseits gelang es nicht, die Unlinearität durch Variation der Testbedingungen $\mathrm{zu}$ beheben. Wegen der komplizierten Abhängigkeiten ist es auch nicht möglich, für bestimmte Proben und Probevolumina eine Temperaturgrenze anzugeben, bis zu der ein geradliniger Reaktionsablauf gewährleistet ist.

Aufgrund der vorgelegten Befunde kann als Meßtemperatur nur $25^{\circ} \mathrm{C}$ empfohlen werden. Schon bei $30^{\circ} \mathrm{C}$ sind einige Seren auch bei Reduktion des eingesetzten Volumens auf $0,5 \mathrm{ml}$ - mit entsprechender Verminderung der Empfindlichkeit des Verfahrens - bei Verwendung bestimmter Triglyceridpräparationen nicht mehr reproduzierbar zu analysieren (Tab. 1).

Auch bei der Messung der katalytischen Aktivität anderer im Serum nachweisbarer Enzyme ist mit steigender Temperatur ein zunehmend unlinearer Substratumsatz zu beobachten (38). Szasz (10) wies bereits 1974 auf die Abweichung von den theoretisch nach Arrhenius (9) zu erwartenden Werten bei zahlreichen klinisch bedeutsamen Fermenten hin. 
Bergmeyer (39) und E. Schmidt (40) haben daher die wesentlichen Argumente sowohl aus dem Bereich der Grundlagenforschung als auch der $\mathrm{MeB}$ technik, die für eine Analyse aller Enzyme bei $25^{\circ} \mathrm{C}$ sprechen, überzeugend zusammengestellt.

1982 (13) machten wir den Zusatz von Colipase, die zwar keine Aktivitätssteigerung in dem verwendeten
Testsystem bewirkt (s. auch 1.c. (12)), es jedoch ermöglicht, eine Hemmwirkung zu hoher Gallensalzkonzentrationen aufzuheben, davon abhängig, ob Colipase in ausreichend reproduzierbarer und definierter Form im Handel vorliegt. Die an 4 Chargen des zur Zeit kommerziell erhältlichen Cofaktors gemachten und beschriebenen Erfahrungen sprechen nicht für den Zusatz von Colipase.

\section{Literatur}

1. Nealon, D. A. (1983) persönliche Mitteilung.

2. Reinigung von Triglyceriden mit Aluminiumoxid, modifiziert nach Tietz, N. W. \& Fiereck, E. A. (1966) Clin. Chim. Acta $13,352-358$.

3. Grubhofer, N. (1983) persönliche Mitteilungen.

4. Rick, W. \& Hockeborn, M. (1983) unveröffentlichte Ergebnisse.

5. Rick, W. (1969) Z. Klin. Chem. Klin. Biochem. 7, 530-539.

6. Tietz, N. W. \& Repique, E. V. (1973) Clin. Chem. 19, 12681275.

7. Granon, S. '\& Sémériva, M. (1980) Eur. J. Biochem. 111, 117-124.

8. Fritz, P. J. \& Melius, P. (1963) Can. J. Biochem. 41, 719730.

9. Arrhenius, S. (1889) Z. Physikal. Chem. 4, 226-248.

10. Szasz, G. (1974) Z. Klin. Chem. Klin. Biochem. 12, 166170.

11. Hofstee, B. H. J. (1952) Science 116, 329-331.

12. Borgström, B. (1982) Biochim. Biophys. Acta 712, 490497.

13. Hockeborn, M. \& Rick, W. (1982) J. Clin. Chem. Clin. Biochem. 20, 773-785.

14. Brockerhoff, H. \& Jensen, R. G. (1974) Lipolytic enzymes. Academic Press, New York pp. 82-83.

15. Borgström, B., Erlanson-Albertsson, C. \& Wieloch, T. (1979) J. Lipid Res. 20, 805-816.

16. Lumper, L. (1964) Grundlagen der Kinetik enzymatisch katalysierter Reaktionen. In: Hoppe-Seyler/Thierfelder, Handbuch der physiologisch- und pathologisch-chemischen Analyse (Lang, K. \& Lehnartz, E., eds.). Springer, Berlin. pp. 1755 .

17. Sarda, L. \& Desnuelle, P. (1961) unveröffentlichte Ergebnisse, zit. nach: Desnuelle, P. (1961) Pancreatic lipase. Adv. Ënzymol. 23, 129-161.

18. Sizer, I. W. \& Josephson, E. S. (1942) Food Research 7, 201-209.

19. Bergmeyer, H. U. (1977) Bestimmung der katalytischen Aktivität von Enzymen. In: Grundlagen der enzymatischen Analyse (Bergmeyer, H. U., ed.). Verlag Chemie, Weinheim pp. 58-81.

20. Maylié, M. F., Charles, M., Gache, C. \& Desnuelle, P. (1971) Biochim. Biophys. Acta 229, 286-289.

21. Erlanson, C., Fernlund, P. \& Borgström, B. (1973) Biochim. Biophys. Acta 310, 437-445.

22. Canioni, P., Julien, R., Rathelot, J., Rochat, H. \& Sarda, L. (1977) Biochimie 59, 919-925.

23. Da Fonseca-Wollheim, F. (1973) Z. Klin. Chem. Klin. Biochem. 11, 421-426.

24. Hummel, B. C. W. (1959) Can. J. Biochem. Physiol. 37, 1393-1399.

25. Erlanson-Albertsson, C. \& Larsson, A. (1981) Biochim. Biophys. Acta $665,250-255$.

26. Lairon, D., Nalbone, G., Lafont, H., Domingo, N. \& Hauton, J. C. (1978) Lipids 13, 211-216.

27. Borgström, B. \& Erlanson, C. (1973) Eur. J. Biochem. 37, 60-68.

28. Patton, J. S. \& Carey, M. C. (1981) Am. J. Physiol. 24I, G328-G336.

29. Rigler, M. W. \& Patton, J. S. (1983) Biochim. Biophys. Acta $751,444-454$.

30. Rick, W. \& Hockeborn, M. (1983) univeröffentlichte Êrgebnisse.

31. Desnuelle, P. (1961) Adv. Enzymol. 23, 129-161.

32. Borgström, B. (1974) Fat digestion and absorption. In: Biomembranes (Manson, M. D., ed.) Vol. 4B, Plenum Publ., New York, pp. 555-620.

33. Verger, R. \& Haas, G. H. de (19̄76) Ann. Rev. Biophys. Bioeng. $5,77-117$.

34. Sémériva, M. \& Desnuelle, P. (1979) Adv. Enzymol. 48, 319-370.

35. Verger, R. (1980) Methods Enzymol. 64, 340-392.

36. Leger, C. \& Charles, M. (1980) Wld. Rev. Nutr. Diet. 35, 96-128.

37. Lairon, D., Nalbone, G., Domingo, N., Lafont, H., Hauton, J., Julien, R., Rathelot, J., Canioni, P. \& Sarda, L. (1975) Lipids 10, 262-265.

38. Rick, W. (1983) unveröffentlichte Ergebnisse.

39. Bergmeyer, H. U. (1973) Z. Klin. Chem. Klin. Biochem. 11, 39-45.

40. Schmidt, E. (1983) Mitt. Dt. Ges. Klin. Chem. 14, 26-29.

Prof. Dr. W. Rick

Institut für Klinische Chemie und Laboratoriumsdiagnostik der Universität Düsseldorf

Moorenstraße 5

D-4000 Düsseldorf 1 